\title{
THE IMPACT OF FINANCIAL INTERDEPENDENCE ON THE CZECH, HUNGARIAN AND POLISH INTERBANK, STOCK AND CURRENCY MARKET
}

\author{
GÁBOR DÁVID KISS \\ UNIVERSITY OF SZEGED, HUNGARY
}

\begin{abstract}
Contagions could be defined as a significant increase in market comovement after a shock to one country, and mostly explained by two theorems: strong cross border relationships between the economies or sudden shifts in market actor's expectations and confidence. The first hypothesis of contagion was accepted on stock market but mostly rejected on interbank and currency market. The second hypothesis, that stock market contagions have the same orientation as trade was rejected. The analysis in this paper employed Dynamic Conditional Correlation GARCH analysis on logarithmic returns to evaluate deviation of market prices from fundamental values under extreme conditions on the selected interbank, stock and currency markets.
\end{abstract}

Keywords: DCC GARCH, interdependence, Visegrad Group

Email: kiss.gabor.david@eco.u-szeged.hu

Tel +36305010578

For tables and figures contact author direct

Acknowledgement: This work was supported by the grant of TÁMOP-4.2.1/B-09/1/KONV-20100005. We appreciate the comments of Dr. Gyula Pap, Dr. Árpád Kovács, Dr. Beáta Farkas Beáta Udvari and Eszter Megyeri.

\section{Introduction}

How can a market influence others? It is a current question for market actors and monetary regulators.
To analyse this phenomena it is necessary to prove that the efficiency of capital markets is weak and to assume a hierarchical linkage inside the market network. If the inter-market correlation is significantly different under shocks, diversification will be ineffective.

This study empirically examines the transmission mechanism of interbank, stock and currency market crashes in the Visegrád Countries, using daily data for the US, Euro area as well as the Czech Republic, Hungary and Poland for the period from January 2002 to October 2010. Particularly, the average level and volatility of inter-market dynamic conditional correlation (DCC) was compared under "normal" and "extreme" conditions of one dedicated ("leader") market - as US and Euro area indicators.

The outline of this paper is the following. First we discuss the theoretical underpinnings between correlations, extreme events under different market models. The Data and Methodology section specifies market effectiveness at first by normality and power-law distribution tests of logarithmic returns as well as stationarity test of market values, than Fischer-transformed GARCH-based DCCs will be compared by two-tailed t-tests and Ansari-Bradley test under leader market's normal and extreme conditions, which are defined by the tails of probability distribution. The results section describes the data and reports the empirical results ending with the conclusion of this article. 


\section{Theoretical background}

Capital markets have crucial role in risk management, where diversification is an basic tool to reduce market risk-notonly in the case of portfolio building, but in the case of maturity transformation too (Marsili-Raffaelli 2006, EisenschmidtHolthausen 2010, Ondo-Ndong 2010, Barrel és mtsai. 2010). The international diversification depends on inter-market correlation, but the benefits of this strategy are eroded by increasing correlation under bear markets as Campbell et al. (2002) suggest. Globalisation and convertibility caused higher level common movement between countries capital markets where economic ties are strong (Chen-Zhang 1997, Goezman et al. 2005). Contagion was defined by Bekaert et al. (2005) and Caporale et al. (2005) as excess correlation over and above what one would expect from economic fundamentals. Forbes-Rigobon (2002) defines contagion more restrictive: it occurs only as a significant increase in cross-market linkages after a shock to one country. If the co-movement does not increase significantly, then any continued high level of market correlation suggests strong linkages between the two economies that exist in all states of the world - which could be defined as interdependence. Therefore the level of significance could be a difference between contagion and interdependence. This significant difference could be caused by enormous capital movements, appearing a gap between the demand and supply side on the market (Wong et al. 2010). Van Royen (2002) and Markwat et al. (2009) pointed out the independence between macro-fundamentals and financial contagions - as it happened under Asian financial crisis in 1997, Russian crisis in 1998 and dot-com crisis in 2001.

Allowance of convertibility caused higher complexity, as Bonano et al. (2001) summarized:

- Stochastic processes are simultaneously characterized by both short range and long range memories and stationary could be only asymptotically.

- For a time horizon of one trading day, 0.7 internal correlations can be observed inside an economic sector.

- Shape of the ensemble return distribution is symmetrical on the typical trading day whereas on extreme days (crashes or rallies) the distribution is skewed (negatively or positively, respectively).

The existence of skewness indicates that extreme market events appear more often as they should be on an efficient market with normal distributed returns. Extreme events and heavy tails are identical as Jetsch et al. (2006) suggest. With the occurrence of heavy tails, there is a lower difference between the probabilities of a medium and a big shift on the market as we expected on Gaussian ground. Alderson (2008) and AlbeveiroPiterbarg (2006) suggest dealing extreme events or heavy tailness as an endogenous property, which came from the market structure.

The Erdősi-Rényi random networks are capable to model competitive and efficient markets with dynamic recombination and fast information propagation, but they are unable to describe preferential connectivity. Scale-free complex networks were described by Barabási-Albert (1999). This model is able to explain internal heterogeneity through preferential connections which could be responsible for spontaneous synchronisations ("large cooperative phenomena") or phase transitions. These systems are far from equilibrium as self-organized criticality (SOC) describes - therefore extreme events are inherent properties of the system and indicated by power law distribution (Wang-Chen 2003, Csermely 2008, Grubestic et al. 2008, Yuan-Wang-Li 2007).

This study aims to validate the model of scalefree complex networks on interbank, stock and currency markets - therefore it is necessary to present: are market comovements significant different under extreme events? The acceptance of this hypothesis suggests the validity of the upper market model and the existence of contagion on the selected market type.

\section{Data and Methodology}

The markets in the sample were selected in order to reconstruct scale-free model hierarchical centre-periphery structure. Farkas (2010), Viturka et al. (2009) and Lengyel (2007) verified such spatial relations in the real economy with a western-European centre and Czech-HungarianPolish periphery. Liu et al. (1998), Chen-Zhang (1997) and Heathcote-Perri (2004) supported the idea, that the shape of connections is parallel with the capital markets as on the real economy. This 
hypothesis could be tested on the stock market sample: Germany is the main trade partner of both sample countries (with $25-30 \%$ share from export and import in 2009), contrary to a marginal US role. Parallelism hypothesis could be accepted, if extreme events on the German DAX index are able much more to separate the significant difference of common movements on the sample (Czech PX, Hungarian BUX and Polish WIG20 indexes) than the US Dow Jones Industrial (DJI) index.

Emerging-Europe sample countries have to adopt the common currency in the future; therefore interbank-market relations were analyzed on overnight $(\mathrm{O} / \mathrm{N})$ relations, between Eurozone's EONIA, Czech Pribor and Hungarian BUBOR. Unfortunately there was lack of data in the case of Poland.

Currency market common movements were tested against EUR/USD is, as CZK/USD, HUF/USD and PLN/USD. Babetskaia-Kukharchuk et al. (2008) and Stavárek (2009) suggested the usage of USD denomination in this case.

The analyzed time horizon covers the post dot-com crisis and the current sub-prime crisis between January 22002 and September 292010.

Time series are logarithmic returns (1) calculated from daily closure values of the selected market indicators with a synchronisation to avoid biases caused by different holydays $(\mathrm{N}=1769)$.

\section{Descriptive statistics}

To test the effectiveness of the analyzed market Jarque-Berra normality test and AugmentedDickey-Fuller (ADF) stationarity test were applied as descriptive tools.

\section{Stationarity analysis (ADF test)}

A stochastic process $\{r t\} T t=1$ is stationary, if its expected value $E(r t)$ and variance $V(r t)$ is a finite constant, and the joint distribution of (rt, rs) depends only on t-s. New information is very rapidly infiltrated into the current market price of an instrument on an efficient market - therefore today's price is the best source to predict tomorrow's price. A price process with this property is called a random walk (2).

$r_{t}=r_{t-2}+\varepsilon_{4}$ where $\varepsilon t$ denote the shock that represents the impact of new information and let rt denote the logarithmic return of an instrument at time $t$.

Discrete time model for a random walk with a drift (3) is

$r_{t}=\alpha+r_{t-1}+\varepsilon_{t}(3)$

where $\alpha$ is a constant representing the drift in the process and which is 0 under pure random walk.

A pth order autoregressive model, denoted $A R(p)$ (4) a special case as well, by adding further lags of $\mathrm{rt}$, for $\mathrm{p}$ an integer greater than 1 .

$r_{t}=\alpha+\varrho_{2} r_{t-1}+\varrho_{2} r_{t-2}+\cdots+\varrho_{v} r_{t-p}+\varepsilon_{t}(4)$

Time series process is said to be integrated of order $\mathrm{i}$ and denoted $\mathrm{I}(\mathrm{i})$ if it is not stationary but its ith difference is stationary. The first difference of an integrated process (5) can have autocorrelated and moving average components:

$R_{t} \sim I(1) \leftrightarrow r_{t}=\alpha+r_{t-1}+\varepsilon_{t}$ (5) , with $\varepsilon_{t} \sim I(0)$ denote that a series is stationary.

The random walk model is just one special type of integrated process, one in which the first difference is independent and identically distributed (IID). When a process is integrated of order 1 it is called as a stochastic trend. For example, the random walk model has a stochastic trend as well as a drift determined by the sign and magnitude of the constant $\alpha$. But the trend in a random walk or in any integrated process is not a deterministic trend (or trend stationary process) (6).

$r_{\mathrm{t}}=\alpha+\beta_{\mathrm{t}}+\varepsilon_{\mathrm{i}}(6)$, where $\varepsilon_{\mathrm{t}} \sim I I D\left(0, \sigma^{2}\right)$

It is important to make a difference between $\mathrm{I}(1)$ behavior and $\mathrm{I}(0)+$ trend behavior due to their transformation requirements to make each process stationary: for a random walk, or indeed any I(1) process, into a stationary series we must take the first difference of the data, while at I(0) + trend process it is enough to take deviations from a fitted trend line.

Empirical evidence (Alexander 2008) suggests that liquid financial markets are quite efficient. In an efficient market, prices are I(1) processes so they follow a stochastic trend and the best prediction of a future price is the price today, plus the drift. When a trend is fitted to the price all this does is 
to remove the drift in the random walk, because it not makes an I(1) process stationary. But trend stationary processes almost never arise in financial markets (Darvas 2004, Alexander 2008).

A market is efficient, if the prices are random walks or follow at least integrated processes. Unit root processes are another type of non stationary processes besides trend stationary process. We say 'inside the unit circle' because one or more of the roots of (4) could be complex numbers. It is only when all the roots are real that the so-called unit root condition reduces to the condition that all roots are less than one in absolute value. This is achieved by adding further lags of $r \mathrm{AR}(1)$ process is $x-\rho=0$ and the unit root condition is therefore simply $|\rho|<1$.

The null hypothesis of $\operatorname{ADF}(q)$ test is non-stationary against the alternative that is stationary (7).

$$
H_{0}: R_{t} \sim \mathrm{I}(1) \text { VS. } H_{2}: R_{t} \sim I\left(0^{\circ} .\right.
$$

This test based on the AR (1) in (4), with the assumption that $\rho 1=1+\beta$. There is a unit root, if $\beta=0$ and $\rho 1$ is not inside the unit circle. We include as many (q) dependent variables as necessary to remove any autocorrelation in the residuals (8).

$$
\Delta r_{t}=\alpha+\beta r_{t-1}+\gamma_{2} \Delta r_{t-1}+\cdots+\gamma_{q} r_{t-q}+\varepsilon_{t}
$$

Thus if the value of test statistic is higher than the prescribed critical region at $1 \%, 5 \%$ and $10 \%$ confidence levels, we cannot reject the null hypothesis, so our time series is non-stationary. An I(1) or I(2) result indicates weaker effectiveness on the market. Type 1 error occurs when the data have jumps or structural beaks - it signs stationarity on non-stationary case too. To avoid such bias, Alexander (2008) and Lütkepohl-Krätzig (2004) suggests testing market values instead of logarithmic returns.

\section{Testing for normal distribution}

The normal distribution of the logarithmic returns (9) is the precondition of efficient market hypothesis - the exponential shape means fast falloff of the returns and the central tendencies are close together (Jentsch és mtsai. 2006). Therefore extreme amplitudes are very improbable (Kóbor 2003).

$$
\text { (9) } \quad f(r)=\frac{2}{\sigma \sqrt{2}-}\left[-\frac{1}{2} \frac{\left(r-\omega^{2}\right.}{\sigma^{2}}\right]
$$

This study applies Jarque-Berra test according Wong-Li (2010), where $\mathrm{P}<5 \%$ value means the rejection of normality.

When stationarity test indicates non-stationary processes and the logarithmic returns have nonnormal distributed, the selected markets are not efficient.

\section{Testing for power-law distribution}

Power law distribution (10) is the most common form of logarithmic returns as Molnár (2006), Gabaix et al. (2003) and Clauset et al. (2009) suggest.

$$
p_{\mathbf{s}}(r)=r^{-=}, 1<\alpha<3 \text { (tail exponent) }
$$

Power-law distributions are indicators of an extraordinarily diverse range of phenomena (Newman 2005). "Perfect storms" of capital markets are characterized by big falls in one equity price, which is accompanied by simultaneous big falls in other equity prices - multivariate normal distributions are unfeasible tools to describe heavy tails (leptokurtosis) or "garden of improbable events". estimated power-law properties were studied deeper by Clauset, Shalizi and Newman's (2009) improved quantile-based maximum likelihood estimation (MLE) method, to estimate the scale parameter $\alpha$. Size of the tails is determined by the scale parameter $\alpha$ - as smaller the $\alpha$, as fatter is the tail. P-values are given by Monte Carlo procedures: the power-law model is fitted for generated synthetic data sets, and the number of times is counted when the Kolmogorov-Smirnov value is larger than observed goodness-of-fit (maximum distance between the tail probability or cumulative distribution function of the empirical data and the fitted power-law model) and in $p \geq 0.05$ case power law distribution hypothesis on the examined side is accepted. (Clauset et al. 2009, Quismorio 2009)

"Extreme events" are defined as outliers on the tails, diverging from fitted normal distribution (11).

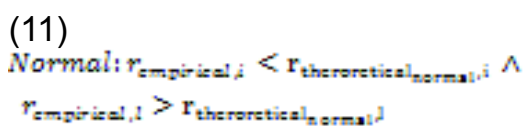




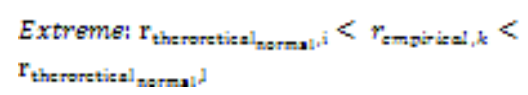

where is the ith element of empirical distribution,

while $r_{\text {theoretical }}$ normal, $i$

is the values of the fitted normal distribution, and $\mathrm{i}<\mathrm{k}<\mathrm{l}$.

This shape is an evidence about the existence of scale-free network structured capital markets - therefore we cannot think about efficient capital markets (Jentsch et al. 2006). The dominant (hub) market could induce deviation between market prices and fundamentals due to the stable hierarchic structure of the system.

While the rejection of stationarity could be the sign of volatility clustering, and the theory of extreme intervals existence is reinforced by power-law distribution too. But how inter-market correlations are affected by the normal or extreme state of hub market (12)?

(12)

$$
\begin{aligned}
& H_{0}: r_{m, 1, \varepsilon x t r m \varepsilon} \rightarrow \rho_{m i, m k, \text { axtrems }} \wedge \\
& r_{m, \text { normal }} \rightarrow \rho_{\text {mi,mk, normal }} \\
& H_{1}: r_{m, \text { strems }} \rightarrow \rho_{m i, m k} \wedge r_{m, n o r m a l} \rightarrow \rho_{m i, m k}
\end{aligned}
$$

where rm1 is the hub markets return, pmi,mk is the correlation between the ith and jth market under the normal and extreme states defined by (11).

\section{Analytic statistics}

To analyze the hub's impact on the inter-market correlation, GARCH based dynamic conditional correlation (DCC) was applied on market returns. Than the calculated DCCs were separated according to the normality and extremity of the hub's return, and the significant difference between the two states of DCCs were tested with 2 sided ttest and Ansari-Bradley test.

Ljung-Box and ARCH LM (Lagrange multiplier) test

When there is a linear dependence between rt and its past values rt-i is of interest, the concept of correlation could be generalized to autocorrelation.
The correlation coefficient between $\mathrm{rt}$ and $\mathrm{rt}-\ell$ is called the lag- $\ell$ autocorrelation of $r$ and it commonly denoted by $\rho \ell$, which under the weak stationarity assumption is a function of $\ell$ only.

This study uses Ljung-Box test as Tsay (2005) and Kuper-Lestano (2007) suggest proving that autocorrelations of $\mathrm{rt}$ are zero with an enhanced Portmanteau statistic. The null hypothesis $\mathrm{HO}$ : $\rho 1=\ldots=\rho m=0$ against the alternative hypothesis $\mathrm{H} 1: \rho 1 \neq 0$ for some $i\{1, \ldots, m\}-$ so is it indepentedly distributed or not.

$$
Q(m)=T(T+2) \sum_{i=1}^{m} \frac{\rho_{\ell}^{2}}{T-\ell}
$$

Under the assumption that $\{r t\}$ is an IID sequence with certain moment conditions, $Q^{*}(m)$ is asymptotically a chi-squared random variable with $\mathrm{m}$ degrees of freedom. The decision rule is to reject $\mathrm{HO}$ if $\mathrm{Q}(\mathrm{m})>\mathrm{x} 2 \alpha$, where $\mathrm{x} 2 \alpha$ denotes the $100(1-\alpha)$ th percentile of a chi-squared distribution with $\mathrm{m}$ degrees of freedom.

It tests for ARCH effects with the null hypothesis of no conditional heteroscedasticity. The rejection of Ho supports the idea of GACH modeling (Lütkepohl 2004).

\section{GARCH modeling}

Series with large outliers (extreme events) and volatility clustering, the conditional second moments may have an important structure as well - bringing on the modeling of autoregression and heteroscedasticity. Based on an univariate $A R(q)$ model (4), the residuals ut are follow an autoregressive conditionally heteroskedastic process of order $q(A R C H(q))$ if the conditional distribution of ut, given its past $\Omega_{\mathrm{t}-1}=\left\{\mathrm{u}_{\mathrm{t}-1}, \mathrm{u}_{\mathrm{t}-2}, \ldots\right\}$, has zero man and the conditional variance (13) is

(14)

$\sigma_{t}^{2}=\operatorname{Var}\left(u_{t} \mid \Omega_{t-1}\right)=E\left(u_{t}^{2} \mid \Omega_{t-1}\right)=\alpha_{0}+$

$\sum_{i=1}^{v} \alpha_{i} u_{i-i}^{2}$

, where $u_{t} \mid \Omega_{t-2} \sim\left(0, \sigma_{t}^{2}\right)$

In this basic form, the ARCH model assumed the conditional distribution to be normal $u_{t} \mid \Omega_{t-1} \sim N\left(0, \sigma_{t}^{2}\right)$, Therefore it is capable of generating series with volatility clustering, and conditional distribution will be normal opposite to 
the generally nonnormal unconditional distribution, while the ut $\mathrm{s}$ will be serially uncorrelated (as white noise) (Lütkepohl 2004, Petrimán-Tulassay 2005).

Volatility persistence and low correlation between successive values of ut2 causes fairly large order (q) for many series, because ARCH process requires them to capture the dynamics in the conditional variances. This means that all the should be positive may not be satisfied if it is not explicitly imposed (Davidson-MacKinnon 2003).

This problem could be solved through the introduction of the lag operator, a generalized $\operatorname{ARCH}(p, q)$ process will be resulted $(14)$ :

$$
u_{t}=\sigma_{t} \varepsilon_{t} ; \sigma_{t}^{2} \equiv E\left(u_{t}^{2} \mid \Omega_{t-1}\right)=\alpha_{0}+
$$$$
\sum_{i=2}^{q} \alpha_{i} u_{t-i}^{2}+\sum_{j=2}^{\eta} \beta_{j} \sigma_{t-j}^{2}
$$

,

where $p$ denotes the length of the lag, $\sigma 2$ and $q$ is the ARCH process, $u 2$ and ai signs the impact of news on the conditional variance, while $\beta$ i means the volatility persistence (Davidson-MacKinnon 2003).

Hence the GARCH $(p, q)$ model is basically symmetric, Kasch-Haroutounian and Price (2001) summarizes its nonlinear (NGARCH), exponential (EGARCH) and their asymmetric versions too.

This purified variance is capable to be a source for dynamic conditional correlation (DCC GARCH).

\section{GARCH}

Ordinary cross-correlation is not the suitable tool to specify the common movement of markets due to the heteroscedasticity as Forbes and Rigobon (2002) suggest. Cointegration is ruled out too, because it is better to analyze long-term processes, so BEKK-GARCH or DCC-GARCH could be an adequate solution.

This study applies DCC-GARCH following KuperLestano (2007) and Wong-Li (2010), to analyze the daily common movements of the selected markets. The DCC model assumes that the returns from $k$ assets, $\mathrm{rt}(15)$, are conditionally multivariate normally distributed with zero expected value and covariance matrix $\mathrm{Ht}$ (16).

$$
\begin{aligned}
& r_{t} \| \Phi_{t-1} \sim N\left(0, H_{t}\right), \\
& H_{t} \equiv D_{t} R_{t} D_{t},
\end{aligned}
$$

where $\mathrm{rt}$ is a $\mathrm{k} 1$ vector, $\mathrm{Ht}$ the positive definite conditional covariance matrix, $\mathrm{Rt}$ the $\mathrm{k} \mathrm{k}$ timevarying correlation matrix, and all available information up to t-1 is contained in $\Phi \mathrm{t}-1$. These returns can be residuals from filtered time series. $D t$ is the $k \quad k$ diagonal matrix of time-varying standard deviations from univariate $\mathrm{GARCH}$ models with $\sqrt{h_{i t}}$ as the ith element of a diagonal. $\mathrm{Dt}$ is obtained from the following univariate $\mathrm{GARCH}$ specification (17):

$$
h_{i t}=\omega_{i}+\sum_{v=-1}^{g_{i}} \alpha_{i p} r_{i t-p}^{2}+\sum_{q=2}^{Q_{i}} \beta_{i q} h_{i t-q}^{2} .
$$

Dividing each return by its conditional standard deviation $\sqrt{h_{i t}}$, one obtains the vector of standardized returns, $\varepsilon_{t}=D_{t}^{-1} r_{t} \quad$ where $\varepsilon_{t} \sim N\left(0, R_{t}\right)$. This vector may be used to write Engle's (2002) specification of a dynamic correlation structure for set of returns $(18,19)$ :

(19)

$Q_{t}=\left(1-\sum_{m=1}^{M} \alpha_{m}-\sum_{n=1}^{N} \beta_{n}\right) \bar{Q}+$

$\sum_{m=2}^{m} \alpha_{m}\left(\varepsilon_{t-m} \varepsilon_{t-m}^{\prime}\right)+\sum_{n=2}^{N} \beta_{n} Q_{t-n}$,

$$
R_{t}=Q_{t}^{-2} Q_{t} Q_{t}^{-2}
$$

where $\bar{Q}$ is the unconditional covariance of the standardized residuals resulting from the first stage estimation and a diagonal matrix composed of the square root of the diagonal elements of Qt. The elements of Rt will be of the form , where qijt, qiit and qjjt are the elements of Qt corresponding to indices. For Rt to be positive definite the only condition that needs to be satisfied is that Qt is a positive definite.

It is necessary to run a Fischer-transformation (20) on the computed correlations for later two sided ttests as Lukács (1999) suggest:

$$
z_{i}=0,5 * \ln \frac{2+r k s_{i}}{2-r s_{i}}
$$

After the identification of market common movements, it is necessary to separate them on the ground of the hub return's extremity or normality. 
Impact of extreme and normal state of the hub market on inter-market correlations

How can we separate the "extreme" and "normal"? Jentsch et al. (2006) defined extreme events by their impact and probability - so we have to find a suitable threshold or milestone to form both groups. There are multiple solutions, see Campbell et al. (2002), but this study focus on the fatness of tails, therefore it is obvious to cut the empirical distribution with a fitted theoretical normal distribution on it (11).

To compare the differences between the Fischer transformed DCCs under normal and extreme hub conditions, two sided t-test and Ansari-Bradley test were done. The t-test assesses whether the means of two groups are statistically different from each other. Ansari-Bradley test of the hypothesis that two independent samples, in the vectors $x$ and $y$, come from the same distribution, against the alternative that they come from distributions that have the same median and shape but different dispersions (e.g. variances). It is reasonable, if the means or variances of market comovements are affected by one dedicated ("hub") market's mood - the acceptance of interdependence hypothesis (12), it will be hard to talk about market efficiency or diversified portfolios.

\section{Results}

Descriptive statistics (see table 1) supported the idea of weak effectiveness - logarithmic returns were non normal distributed as $p=0 \%$ results of Jarque-Bera test suggested, but power-law distributed. Tails were longer on the positive side of the currency distribution, indicating higher variety of extreme events under depreciation. Interbank markets had too heavy tails; these markets had some kind of "Z" shape instead of usual "S" on $Q Q$ plots. This result shows a paradox picture: even stock markets are closer to normality than centralbank managed interest rates.

The lack of stationarity was shown by AugmentedDickey-Fuller (ADF) test, all market followed at least I(1) process.

The Ljung-Box $Q$ statistics at 36 lags are computed for both the series and squared series. The Qstatistics indicate the presence of significant linear and non-linear dependencies. The first type of dependencies may be due to some form of market inefficiency or market structure while autoregressive conditional heteroscedasticity may cause a latter type of dependency. Only EUR/ USD and CZK/USD pairs presented the lack of significant autocorrelations. The ARCH tests also support the presence of autoregressive conditional heteroscedasticity. The null hypothesis of no $\mathrm{ARCH}$ is clearly rejected at $5 \%$ significance level, which means that the residuals had conditional heteroscedasticity (Kuper-Lestano 2007).

Figure 1 illustrates the density of extreme events on each market - there is no clear border between "normal" and "crisis" intervals, but local density of extremes indicate the occurrence of sub-prime crisis.

Hence descriptive statistics underlined the rejection of efficient market hypothesis, proving contagions demands to analyze particular extreme events on network level. Table 2 summarizes the results of t-test and Ansari-Bradley tests on Fischer transformed dynamic conditional correlations (DCC). Significantly different common movements under "normal" and "extreme" circumstances indicate the existence of contagion.

There were two hypotheses in this study: the first one deal with the existence of contagion on the different market types, while the second seeks for trade-oriented background of stock market contagions.

According to the results of table 2 , the firsthypothesis was accepted on the stock markets - but only with the rejection of the second hypothesis. Emerging European stock market common movements could be split on the significantly different parts only by the US Dow Jones Industrial index's normal and extreme states. The German DAX index had weaker explanatory power both in the case of ttest and Ansari-Bradley test. These results are similar to suggestions by Eun-Shim (1989) about the leader role of US capital markets.

There was weaker evidence on contagions in the case of interbank and currency markets. Significant differences were in the variance of correlations only in the half of the combinations. These results indicate a time- and mood-variant correlation, but without an exact "leader-market". Extreme fat tails on the interbank markets could be an explanation on contagion difficulties - not to mention the unique monopoly role of central banks. Gabaix (2003) underlines that fat-tails occurring in connection with the operation of hub actors - creating a specific paradox of regulations, 
lack of contagion and higher preference of extreme phenomena.

\section{Conclusion}

US determined contagions were identified on the stock markets - with significantly higher level and variety of correlation. This synchronizing phenomenon makes impossible any diversification.

Interbank-makers are more disintegrated, but characterized by more extremity. Currency markets are between these two border-line cases.

Networks of capital markets and real economies are not parallel, previous is Germany oriented, while latter is US dominant.

Capital market actors are responsible to manage risks in a post Breton Woods era as Urlich Beck's "insurgency society" theory suggests (Jentsch et al. 2006). Therefore circle of crises could not be solved with a network disintegration trough decreasing convertibility. Stronger liquidity and capital adequacy standards for strategic hub actors are more capable tools to avoid extreme synchronizations as well as forming state managed buffers like traditional reserves or sovereign wealth funds.

\section{References}

Albeverio, S., Piterbarg, V. 2006. Mathematical Methods and Concepts. In: Albeverio S., Jentsch V., Kantz H. (eds.) 2005. Extreme Events in Nature and Society. Springer

Alexander C. 2008. Market Risk Analysis: Practical Financial Econometrics (v. 2). Wiley

Alderson, D. L. 2008. Catching the "Network Science" Bug: Insight and Opportunity for the Operations Researcher. Operations Research, Vol. 56, No. 5, September-October 2008, pp. 1047-1065

Babetskaia-Kukharchuk O., Babetskii I., Podpiera J. 2008. Convergence in exchange rates: market's view on CE-4 joining EMU. Applied Economics Letters, 15, pp. 385-390
Barabási, A.-L. - Albert, R. 1999 Emergence of Scaling in Random Networks. Science, vol. 286, p. 509; DOI: 10.1126/science.286.5439.509

Barrel R., Davis E. P., Karim D., Liadze I. 2010. Calibrating Macroprudential Policy. Euroframe

Bekaert, G., Harvey, C. R., Ng, A. 2005. Market Integration and Contagion. Journal of Bussiness. vol. 78 , no. 1 , pp. 39-69

Blanchard, P., Krüger, T. 2006. Networks of the Extreme: A Search for the Exceptional. In: Albeverio S., Jentsch V., Kantz H. (eds.) 2005. Extreme Events in Nature and Society. Springer

Bonano, G., Lillo, F., Mantegna, R. 2001. Levels of complexity in financial markets. Physica A, 299 pp. $16-27$

Campbell, R., Koedij, K., Kofman, P., 2002. Increased Correlation in Bear Markets. Financial Analysts Journal, Jan/Feb 2002, 58 (1) pp. 87-94

Caporale, G. M., Cipollini, A., Spagnolo, N., 2005. Testing for contagion: a conditional correlation analysis. Journal of empirical finances, 12 pp. 476489.

Chen, N., Zhang, F. 1997. Correlations, trades and stock returns of the Pacific-Basin Markets. PacificBasin Finance Journal, Vol. 5, pp. 559-577

Clauset A., Shalizi C.R., Newman M.E.J. 2009. Power-law distributions in empirical data. SIAM Review 51 (4), pp. 661-703

Csermely, P. 2008 Creative elements: networkbased predictions of active centres in proteins and cellular and social networks. Trends in Biochemical Sciences, 33 (12) pp. 569-576; doi:10.1016/ j.tibs.2008.09.006

Darvas Zs. 2004. Bevezetés az idősorelemzés fogalmaiba. Jegyzet, Budapest, 2004. október 14.

Davidson, R., MacKinnon, J. G. 2003. Econometric Theory and Methods. Oxford University Press, New York.

Engle, R. 2002. Dynamic Conditional Correlation: A Simple Class of Multivariate Generalized Autoregressive Conditional Heteroscedasticity Models. Journal of Business and Economic Statistics, 20, pp. 339-350. 
Eisenschmidt J., Holthausen C. 2010. The minimum liquidity deficit and the maturity structure of central bank's open market operations: lessons from the financial crisis. Euroframe

Eun, C. S., Shim, S. 1989. International Transmission of Stock Market Movements. Journal of Financial and Quantitative Analysis, 24 (2) pp. 241-256

Farkas, B. 2009 Új tagállamok, új model? SZTE GTK Mühelytanulmányok, MT-PNGKI - 2009/1

Forbes, J. K., Rigobon, R., 2002. No contagion, only interdependence: measuring stock market comovements. Journal of Finance, 57 (6) pp. 2223-2261

Gabaix X., Gopikrishnan P., Plerou V., Stanley H. E. 2003. A theory of power-law distributions in financial market fluctuations. Nature 423, pp. $267-$ 270

Goetzmann, W. N., Li, L., Rouwenhorst, K. G. 2005. Long-Term Global Market Correlations. Journal of Business, vol. 78, no. 1, pp. 1-28

Grubesic, T. H. - Matisziw, T. C. - Murray, A. T. - Snediker, D. 2008 Comparative Approaches for Assessing Network Vulnerability. International Regional Science Review, vol. 31; no. 88; DOI: 10.1177/0160017607308679

Heathcote, J., Perri, F. 2004. Financial globalization and real regionalization. Journal of Financial Theory, Vol. 119, pp. 207-243

Jentsch, V., Kantz, H., Albeverio, S. 2006. Extereme Events: Magic, Mysteries and Challenges. In: Albeverio S., Jentsch V., Kantz H. (eds.) 2005. Extreme Events in Nature and Society. Springer

Kasch-Haroutounian M., Price S. 2001. Volatility in the transition markets of Central Europe. Applied Financial Economics, 2001, 11, 93-105

Kóbor Á. 2003. A piaci kockázatmérési eszközök alkalmazási lehetőségei a pénzügyi stabilitás elemzésében. Ph.D. értekezés, BKÁE, Budapest

Kuper, G. H., Lestano 2007. Dynamic Conditional Correlation Analysis of Financial Market Interdependence: An Application to Thailand and Indonesia. Journal of Asian Economics, Vol. 18, pp. $670-684$
Lengyel I. 2007 Fejlesztési pólusok, mint a tudásalapú gazdaság kapuvárosai. Magyar Tudomány, vol. 6, p. 749-758

Liu, Y. A., Pan, M-S., Shieh, C. P. 1998. International Transmission of Stock Price Movements: Evidence from the U.S. and Five Asian-Pacific Markets. Journal of Economics and Finance, Vol. 22, No. 1, pp. $59-69$

Lukács O. 1999. Matematikai Statisztika. Müszaki Könyvkiadó, Budapest

Lütkepohl, H. 2004. Univariate Time Series Analysis. In: Lütkepohl, H., Kratzig, M. (eds.): Applied Time Series Econometrics, Cambridge University Press

Markwat, T., Kole, E., Dijk, D. 2009. Contagion as a Domino Effect in Global Stock Markets. Journal of Banking and Finance, vol. 33, pp. 1996-2012

Marsili, M., Raffaelli, G. 2006. Risk Bubbles and Market Instability. Phisica A, vol. 370, pp 18-22

Molnár M. B. 2006. A hatékony piacokról szóló elmélet kritikái és empírikus tesztjei. Hitelintézeti Szemle, 2006, 5 (3) pp. 44-62

Newman, M. E. J. 2005. Power laws, Pareto distributions and Zipf's law. Contemporary Physics, 46 (5) pp. 323 - 351

Ondo-Ndong S. 2010. Is there a case for maturity mismatch and capital ratios as complementary measures to identify risky banks and trigger for supervisory intervention? Euroframe

Petrimán Z., Tulassay Zs. 2005. Bepillantás az ARCH modellek világába. Hitelintézeti Szemle, 2005. IV. évf. 2. sz

Quismorio, B. A. 2009. The Tail Distribution of the Philippine Stock Price Index. Working Paper, University of Philippines-Diliman

Stavárek, D. 2009. Assessment of the Exchange Rate Convergence in Euro-Candidate Countries. Amfiteatru Economic Journal, 11, 25, pp. 159180.

Tsay, Ruey S. 2005. Analysis of Financial Time Series. John Wiley and Sons

Van Royen, A-S. 2002. Financial Contagion and International Portfolio Flows. Financial Analysts Journal, vol. 58, no. 1, pp. 35-49 
Viturka, M. - Zítek, V. - Klímová, V. - Tonev, P. 2009 Regional Analysis of New EU Member States in the Context of Cohesion Policy. Review of Economic Perspectives, vol. 9, no. 2, p. 71-90

Wang, X. F., Chen, G. 2003: Complex networks: small-world, scale-free and beyond. Circuits and Systems Magazine, IEEE, 3, 1, pp. 6-20

Wong, D. K. T., Li, K-W. 2010. Comparing the Performance of Relative Stock Return Differential and Real Exchange Rate in Two Financial Crises. Applied Financial Economics, Vol. 20, pp. 137150

Yuan, B. - Wang, B.-H. - Li, B. 2007 Evolutionary Dynamics in Complex Networks of Adaptive and Competing Agents. Great Eastern Life Assurance Co. 